\title{
Prognosis after intrahepatic recurrence in the patients who underwent curative resection for hepatocellular carcinoma
}

\author{
Juhyeon Lee ${ }^{1}$, Eung-Ho Cho ${ }^{1}$, Sang Bum Kim ${ }^{1}$, and Ryounggo $\mathrm{Kim}^{2}$ \\ ${ }^{1}$ Department of Surgery, Korea Cancer Center Hospital, Seoul, \\ ${ }^{2}$ Department of Surgery, Dongnam Institution of Radiological \& Medical Sciences, Busan, Korea
}

\begin{abstract}
Backgrounds/Aims: Intrahepatic recurrence is frequent result after hepatectomy for hepatocellular carcinoma (HCC). We analyzed the clinical results of patients who had the intrahepatic recurrences of HCC after curative surgical resections. Methods: From January 2009 to December 2016, 320 patients underwent curative surgical resection for HCC in department of Surgery, Korea Cancer Center Hospital. After surgical resection, 155 patients had suffered HCC recurrence during follow-up period. Among them, 122 patients had only intrahepatic recurrence initially, who were included in this retrospective study. We analyzed about the period of the recurrence after surgery, treatment methods for the recurred tumors, and poor prognostic factors for survival after intrahepatic recurrences. Results: Among the 122 patients, 83 patients had recurrence within 24 months after surgery. Thirty-eight patients underwent curative treatment for the recurred tumors (re-resection in 18, radiofrequency ablation in 20 patients). Non-curative treatments were performed in 77 patients (TACE in 68 patients, radiotherapy in 9 patients) and conservative management in 7 patients. Five-year survival rate of patients who underwent curative treatment is $86.4 \%(p \leq 0.001)$. Five-year survival rate of non-curative treatment is $55.7 \%(p \leq 0.001)$, conservative management is $0 \%(p=0.021)$. Among the clinical factors, non-curative treatment for recurred tumor, AFP level at the time of recurrence, size of recurred tumor were independent poor prognostic factors for survival after intrahepatic recurrences $(p<0.001)$. Conclusions: For the patients who had intrahepatic recurrent $\mathrm{HCC}$ after surgery, aggressive local treatment can improve the prognosis in selective cases. Further study is necessary to validate this retrospective investigation. (Ann Hepatobiliary Pancreat Surg 2020;24:431-436)
\end{abstract}

Key Words: Hepatocellular carcinoma; Intrahepatic recurrence; Survival

\section{INTRODUCTION}

Hepatocellular carcinoma (HCC) is among the most common malignant neoplasms worldwide. The patient outcomes after the resection of HCC have improved because of the development in surgical techniques and perioperative care. ${ }^{1,2}$ However, the high incidence of intrahepatic recurrence (IHR) remains a major challenge in the treatment of HCC. ${ }^{1}$ Furthermore, IHR has been extensively studied because it is 6-7 times more common than extrahepatic recurrence. ${ }^{3}$ Moreover, the liver is the predominant site of the first recurrence after the resection of HCC, and survival is poor after recurrence occurs. ${ }^{4}$ The cumulative 5-year recurrence rate was $70-80 \%$, and the most common site of recurrence was the remnant liver. ${ }^{5}$
The 1-year, 3-year, and 5-year overall survival rates after recurrence in patients with intrahepatic nodular recurrence were $91.0 \%, 71.0 \%$, and $37.5 \%$, respectively. Therefore, it is important to determine how this group of patients should be treated. ${ }^{6}$

There are some treatment options for IHR of HCC, and surgical resection is the best treatment for IHR. ${ }^{2}$ Repeat hepatic resection might be the most effective treatment for IHR, and the 5-year survival after re-resection ranged from $31 \%$ to $69 \%$. $^{7-9}$ However, re-resection might be difficult in some cases because of adhesion, modifications in the anatomy, and impaired liver function. ${ }^{10,11}$

Many studies have evaluated the treatment for IHR of HCC. For example, for patients with a solitary tumor recurrence after resection, repeat hepatectomy, local abla-

Received: July 1, 2020; Revised: August 31, 2020; Accepted: September 1, 2020

Corresponding author: Eung-Ho Cho

Department of Surgery, Korea Cancer Center Hospital, 75 Nowon-ro, Nowon-gu, Seoul 01812, Korea Tel: +82-2-970-1218, Fax: +82-2-970-2419, E-mail: gsceh@kcch.re.kr

Copyright (C) 2020 by The Korean Association of Hepato-Biliary-Pancreatic Surgery

This is an Open Access article distributed under the terms of the Creative Commons Attribution Non-Commercial License (http://creativecommons.org/ licenses/by-nc/4.0) which permits unrestricted non-commercial use, distribution, and reproduction in any medium, provided the original work is properly cited. Annals of Hepato-Biliary-Pancreatic Surgery • pISSN: 2508-5778 - eISSN: 2508-5859 
tion therapy, and transhepatic arterial chemoembolization (TACE) may contribute to long-term survival, even if disease recurrence occurs. ${ }^{5}$ Local thermal and chemical ablation therapies include percutaneous ethanol injection, microwave ablation, and radiofrequency ablation (RFA), all of which are reported to improve the survival rate of patients with IHR. ${ }^{2}$ The most frequent treatment for IHR is TACE because of the large tumor size, presence of multiple intrahepatic tumors, unfavorable tumor location, or limited residual liver function reserve and poor liver function. ${ }^{5,6,10,11}$ Moreover, most cases of multiple-diffuse recurrences are inevitably managed with repeated TACE or chemotherapy. ${ }^{12,13}$

Radiation therapy is a safe and effective treatment for patients with recurrent unresectable HCC. ${ }^{14,15}$ Recent technological developments in radiation therapy, such as stereotactic body radiation therapy (SBRT) and imaged-guided radiotherapy, have made it possible to deliver a substantial dose of radiation to the tumor and avoid the radiosensitive normal liver in the vicinity. ${ }^{16}$

The aim of the current study was to analyze the clinical outcomes of patients with IHRs of HCC after surgical resection in our institution.

\section{MATERIALS AND METHODS}

\section{Patients}

Between January 2009 and December 2016, a total of 320 patients underwent curative surgical resection for HCC in the Department of Surgery, Korea Cancer Center Hospital, Seoul, Republic of Korea. After surgical resection, patients underwent regular blood and imaging tests every 3 months during the first year of follow-up, after which they were examined regularly every 4-6 months during follow-up. A total of 155 patients showed HCC recurrence during the follow-up period. Among the 155 patients, 122 patients had only IHR initially. These

Table 1. Number of recurrent patients (number of all cases $(\mathrm{n}=320))$

Number of recurrent patients during the follow up period

\begin{tabular}{lr}
\hline No evidence of disease & 165 \\
Intrahepatic recurrences & 122 \\
Extrahepatic recurrences \pm intrahepatic recurrences & 33 \\
\hline
\end{tabular}

122 patients were included in the current retrospective study (Table 1). We analyzed the period between the primary surgery and recurrence, treatment methods for the recurrent tumors, and poor prognostic factors for survival after IHR for the 122 included patients. We classified these 122 patients into two groups according to the time of recurrence after the primary surgery: 83 patients showed IHR within 24 months after the primary surgery which is early recurrence group, and the remaining 39 patients showed recurrence 24 months after the primary surgery which is late recurrence group (Table 2). We then analyzed the 122 patients for determining the survival rate after the initial recurrence. We analyzed each patient's survival period from the time we found the initial recurrence (IRB no. KIRAMS-2020-04-016).

\section{Clinicopathological variables}

The evaluated clinicopathological variables included the time from the primary operation to the first recurrence, the alpha-fetoprotein (AFP) level at the time of recurrence, the size of the recurrent tumor, the number of IHRs, and the presence of cirrhosis.

\section{Curative and non-curative therapy}

Surgical resection and RFA are potentially curative treatment modalities for HCC. ${ }^{17}$ TACE, systemic therapy, and SBRT are non-curative treatments. In the current study, only the initial treatment was used for statistical analysis.

\section{Statistical analysis}

We obtained the data from the medical records of patients. The data were analyzed retrospectively, using IBM SPSS statistics (Korean Version 23), Kaplan-Meier analysis, Chi-square analysis and Cox regression analysis. $p$-values less than 0.05 were considered statistically significant.

Table 2. The period of recurrence

\begin{tabular}{cc}
\hline $\begin{array}{c}\text { Time period of recurrence from } \\
\text { primary operation }\end{array}$ & $\begin{array}{c}\text { Number of } \\
\text { cases }(\mathrm{n}=122)\end{array}$ \\
\hline$\leq 24$ months (early recurrence group) & 83 \\
24 months $<$ (late recurrence group) & 39 \\
\hline
\end{tabular}




\section{RESULTS}

\section{Survival rates of patients with intrahepatic recurrence}

The 5-year overall survival rate of the 122 included patients with initial IHR was $62 \%$, and the 10 -year overall survival rate was $55.1 \%$ after initial recurrence (Fig. 1).

\section{Curative and non-curative therapy}

Curative treatment for the recurrent tumors was performed for 38 patients (re-resection for 18 patients and RFA for 20). Non-curative treatments were performed for 77 patients (TACE for 68 patients, radiotherapy for 9) and conservative management for 7 (Table 3).

\section{Association between time of recurrence after the primary surgery and survival}

The 5-year survival rate was $90.3 \%$ for patients of late recurrence group and $52.8 \%$ for patients of early re-

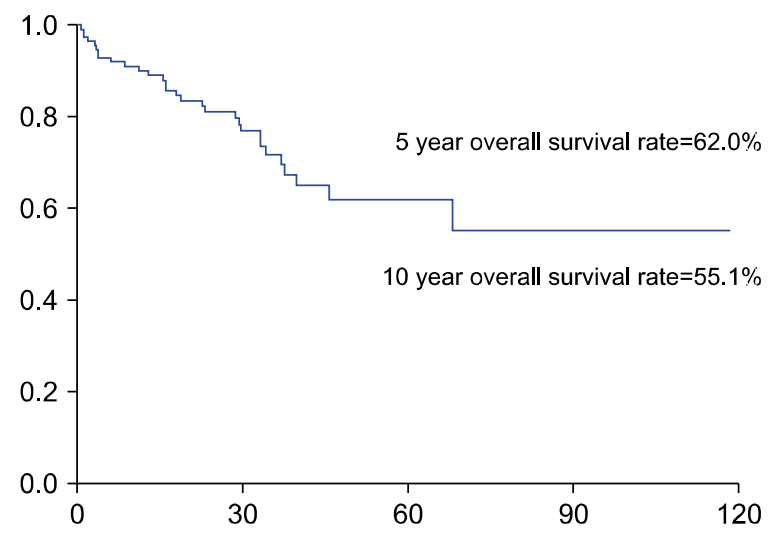

Fig. 1. Five-year overall survival rate of 122 patients after initial IHR is $62 \%$, and 10 -year overall survival is $55.1 \%$.

Table 3. Treatment modality after IHR

\begin{tabular}{lr}
\hline Treatments for IHR & No \\
\hline Curative Tx & \\
Re-resection & 18 \\
RFA & 20 \\
Non-curative Tx & \\
TACE & 68 \\
RT & 9 \\
Conservative care & 7 \\
Total & 122 \\
\hline
\end{tabular}

Tx, treatment; RFA, radiofrequency ablation; TACE, transhepatic arterial chemoembolization; RT, radiotherapy currence group. The survival rate was higher when the time between the surgery and the recurrence was longer ( $p=0.015$; Fig. 2).

\section{Clinical features}

We analyzed the clinical features of the patients with IHR according to the period between the primary surgery

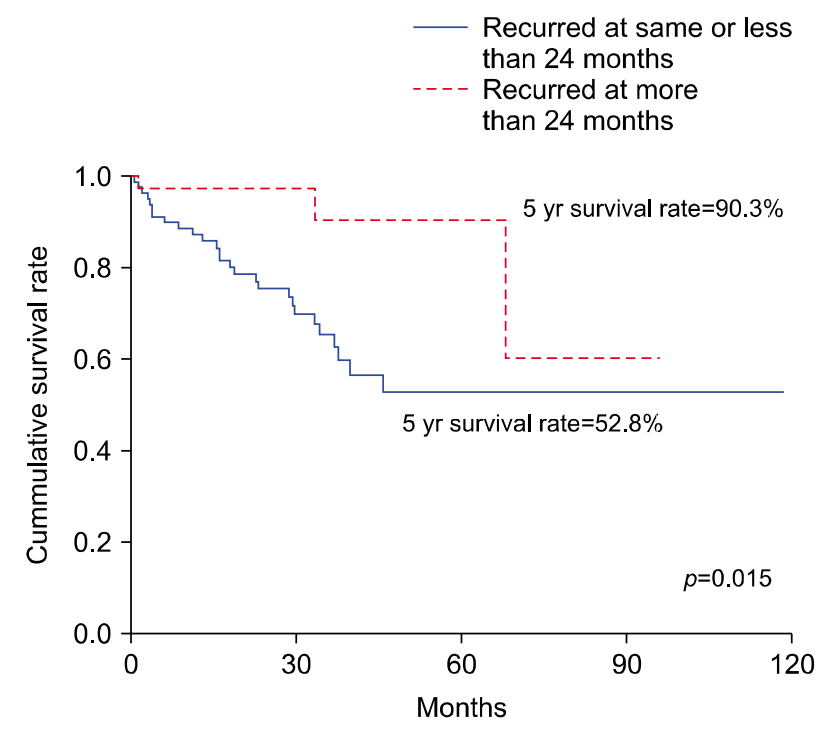

Fig. 2. The 5-year survival rate was $90.3 \%$ for patients of late recurrence group and $52.8 \%$ for patients of early recurrence group. The survival rate was higher when the time between the surgery and the recurrence was longer $(p=0.015)$.

Table 4. Clinical features of patients with IHR according to the time period of recurrence

\begin{tabular}{|c|c|c|c|}
\hline \multirow{3}{*}{ Variables } & \multicolumn{2}{|c|}{ Number of patients } & \multirow{3}{*}{$p$-value } \\
\hline & $\begin{array}{l}\text { Time pe } \\
\text { primary }\end{array}$ & eriod from & \\
\hline & $\begin{array}{l}\leq 24 \\
\text { months }\end{array}$ & $\begin{array}{c}24 \\
\text { months }<\end{array}$ & \\
\hline Size of recurred tumor & & & 0.189 \\
\hline$\leq 3 \mathrm{~cm}$ & 72 & 37 & \\
\hline $3 \mathrm{~cm}<$ & 11 & 2 & \\
\hline Number of recurred tumors & & & $<0.001$ \\
\hline Single & 33 & 30 & \\
\hline Multiple & 50 & 9 & \\
\hline $\begin{array}{l}\text { AFP level at the time of } \\
\text { recurrence }(\mathrm{ng} / \mathrm{dl})\end{array}$ & & & 0.031 \\
\hline$\leq 200$ & 67 & 37 & \\
\hline $200<$ & 16 & 2 & \\
\hline $\begin{array}{l}\text { Initial treatment for the } \\
\text { recurrence }\end{array}$ & & & $<0.001$ \\
\hline Curative & 20 & 18 & \\
\hline Non-curative & 57 & 20 & \\
\hline Conservative & 6 & 1 & \\
\hline
\end{tabular}


and recurrence (Table 4). Early recurrence group patients were more likely to have large, multiple recurrent tumors and the AFP level tended to exceed $200 \mathrm{ng} / \mathrm{ml}$. We analyzed the initial treatment for the recurrent tumor as well. Curative treatment was performed for 20 of the 83 patients of early recurrence group and for 18 of the 39 patients in late recurrence group. The curative treatment was more frequently performed in late recurrence group than early recurrence group.

\section{Patient outcomes after the treatment for intrahepatic recurrence}

Among the 122 patients with IHR, the survival rate was significantly better for patients who underwent curative therapy than for those who underwent other therapies (Fig. 3). The prognosis was good when curative treatment

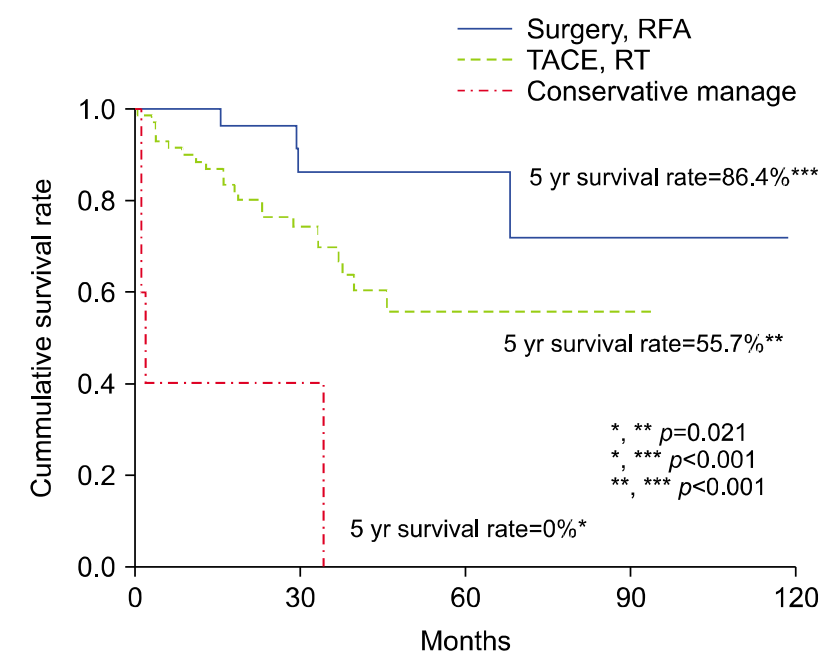

Fig. 3. Survival rate of patients who had curative treatment was $86.4 \%$. Survival rate of patients who had non-curative treatment was $55.7 \%$, conservative management was $0 \%$ $(p=0.05)$.
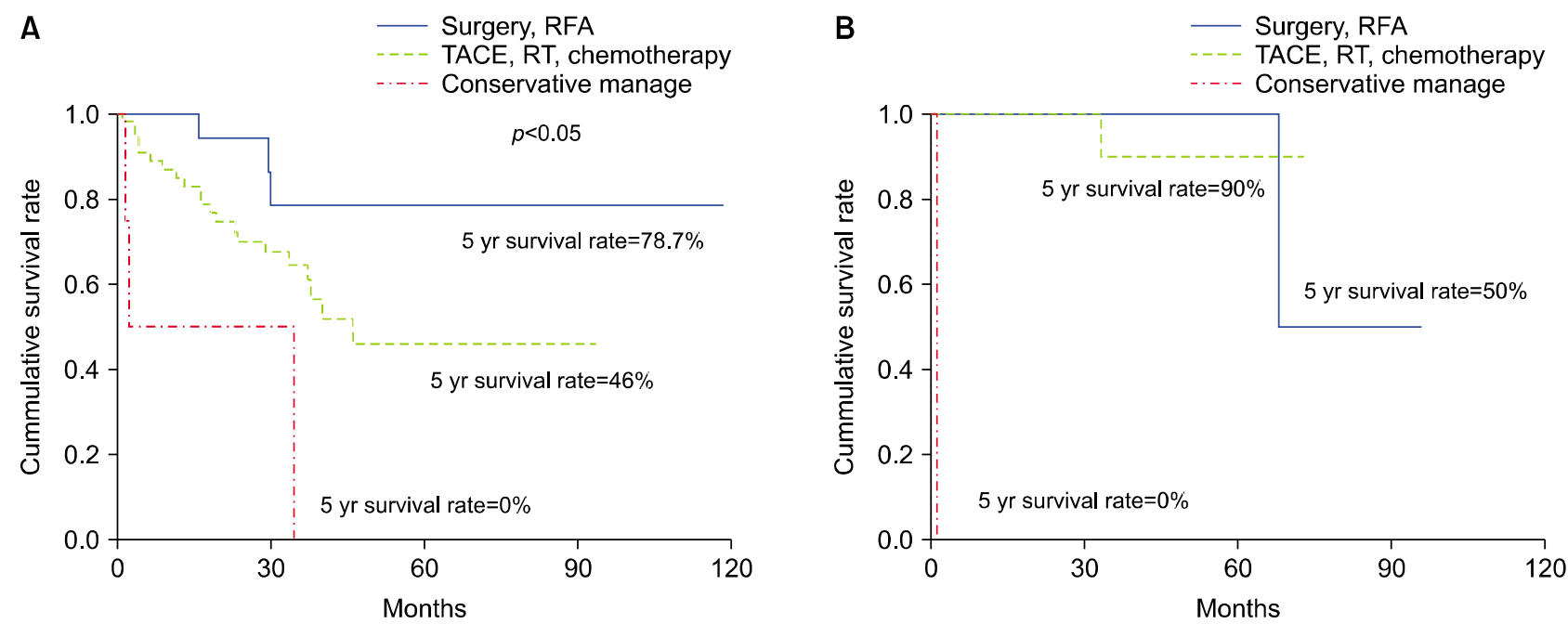

Fig. 4. Prognosis is better when performing curative treatment in early recurrence group. (A) The survival rate according to the method of treatment was significantly different in early recurrence group $(p<0.05)$. (B) There was no difference in late recurrence group in late recurrence group.

Table 5. Independent poor prognostic factors for survival after intrahepatic recurrence

\begin{tabular}{|c|c|c|c|c|}
\hline \multirow{2}{*}{ Variables } & \multirow{2}{*}{$\begin{array}{c}\text { Univariate } \\
\text { analysis }\end{array}$} & \multicolumn{3}{|c|}{ Multivariate analysis } \\
\hline & & $p$-value & Exp (B) & $95 \% \mathrm{CI}$ \\
\hline Age $(65$ years <) & 0.400 & & & \\
\hline Sex & 0.502 & & & \\
\hline Period for recurrence (less than 12 months) & 0.015 & 0.330 & & \\
\hline Number (multiple) & 0.004 & 0.181 & & \\
\hline Non-curative treatment for recurred tumor & $<0.001$ & 0.037 & 0.275 & $0.082-0.925$ \\
\hline AFP level at the time of recurrence $(200 \mathrm{ng} / \mathrm{dl} \leq)$ & $<0.001$ & 0.002 & 0.255 & $0.112-0.578$ \\
\hline Size of recurred tumor $(3 \mathrm{~cm}<)$ & $<0.001$ & 0.003 & 0.218 & $0.086-0.556$ \\
\hline
\end{tabular}

AFP, alpha-fetoprotein 
was performed in early recurrence group. The survival rate according to the method of treatment was significantly different in early recurrence group $(p<0.05)$, however there was no difference in late recurrence group (Fig. 4).

\section{Independent poor prognostic factors for survival after intrahepatic recurrence}

Among the clinical factors, the independent poor prognostic factors for survival after IHRs were non-curative treatment for recurred tumor, AFP level at the time of recurrence, size of recurred tumor (Table 5).

\section{DISCUSSION}

In the current study, the survival rate was better after aggressive local treatment than after non-curative treatment and conservative treatment for patients with IHR after the primary surgery. Our results show that curative therapy is indicated for patients with IHR after primary surgery because a good prognosis is predicted. However, the selection bias for curative treatment might have influenced the results of good prognosis. This is because patients who cannot choose re-resection or RFA are more likely to have diffuse or large recurrent tumors, poor liver function, and insufficient remnant liver volume. Moreover, these conditions would have resulted in a bad prognosis. Furthermore, only a few patients who showed recurrence after 24 months might have died after the short follow-up, which may have affected statistical results.

Many studies analyzed the prognostic factors of IHR, which were the presence of portal vein invasion, multiple primary HCC tumors, a high serum AFP level, a large tumor, the presence of cirrhosis, and increased age, among others. Moreover, the number of primary HCC tumors was a significant predictor of disease-free survival after hepatic resection. However, only a few studies have evaluated the prognostic factors of survival after IHR. In a previous study, a period of $<1$ year to recurrence and the presence of multiple IHRs were unfavorable prognostic factors. Furthermore, a low ICGR (Indocyanine green retention), the absence of cirrhosis, and the absence of portal vein invasion were significantly favorable prognostic factors after recurrence. ${ }^{2,13}$ In the current study non-curative treatment for recurred tumor, the AFP level at the time of recurrence, and the size of the recurrent tumor were independent poor prognostic factors for survival after IHRs.

Patients are not usually treated with one method but with a combination of various methods. Therefore, it was difficult to analyze the administered treatment because there were many different combinations of treatments. Hence, in the current study, we considered the initial treatment. Curative treatment resulted in better prognosis than non-curative and conservative treatment for patients with IHR after primary resection in the early recurrence group. The survival rate tended to be distinctly better patients who received curative treatment in early recurrence group. Nevertheless, as the follow-up period was relatively short, late recurrence group patients might have shown fewer deaths. Accordingly, the differences in treatment methods were not clearly analyzed.

In summary, the independent poor prognostic factors of patients with intrahepatic recurrence after curative initial surgery are AFP level at the time of recurrence, size of recurred tumor and aggressive local treatment.

In conclusion, aggressive local treatment can improve the prognosis in selected patients with IHR of HCC after surgery. Nevertheless, further studies are necessary to validate the findings of the current retrospective investigation.

\section{CONFLICT OF INTEREST}

The authors declare that there are no conflicts of interest regarding the publication of this article.

\section{ORCID}

Juhyeon Lee: https://orcid.org/0000-0001-5066-8197

Eung-Ho Cho: https://orcid.org/0000-0001-6273-4411

Sang Bum Kim: https://orcid.org/0000-0002-0802-4686

Ryounggo Kim: https://orcid.org/0000-0002-7257-6821

\section{AUTHOR CONTRIBUTIONS}

Conceptualization: EHC. Data curation: JL, EHC, SBK, RK. Data analysis: JL, EHC, SBK Methodology: EHC, RK. Project administration: SBK, RK. Visualization: EHC. Writing - original draft: JL, EHC. Writing - review 
\& editing: JL.

\section{REFERENCES}

1. Kew MC. Recurrence of hepatocellular carcinoma after surgery: can it be avoided? Hepatology 1996;24:741-742.

2. Kawano Y, Sasaki A, Kai S, Endo Y, Iwaki K, Uchida H, et al. Prognosis of patients with intrahepatic recurrence after hepatic resection for hepatocellular carcinoma: a retrospective study. Eur J Surg Oncol 2009;35:174-179.

3. Hanazaki K, Matsushita A, Nakagawa K, Misawa R, Amano J. Risk factors of intrahepatic recurrence after curative resection of hepatocellular carcinoma. Hepatogastroenterology 2005;52:580586.

4. Cha C, Fong Y, Jarnagin WR, Blumgart LH, DeMatteo RP. Predictors and patterns of recurrence after resection of hepatocellular carcinoma. J Am Coll Surg 2003;197:753-758.

5. Hirokawa F, Hayashi M, Miyamoto Y, Asakuma M, Shimizu T, Komeda K, et al. Appropriate treatment strategy for intrahepatic recurrence after curative hepatectomy for hepatocellular carcinoma. J Gastrointest Surg 2011;15:1182-1187.

6. Choi GH, Kim DH, Kang CM, Kim KS, Choi JS, Lee WJ, et al. Prognostic factors and optimal treatment strategy for intrahepatic nodular recurrence after curative resection of hepatocellular carcinoma. Ann Surg Oncol 2008;15:618-629.

7. Imamura H, Matsuyama Y, Tanaka E, Ohkubo T, Hasegawa K, Miyagawa S, et al. Risk factors contributing to early and late phase intrahepatic recurrence of hepatocellular carcinoma after hepatectomy. J Hepatol 2003;38:200-207.

8. Umeda Y, Matsuda H, Sadamori H, Matsukawa H, Yagi T, Fujiwara T. A prognostic model and treatment strategy for intrahepatic recurrence of hepatocellular carcinoma after curative resection. World J Surg 2011;35:170-177.

9. Notake T, Kobayashi A, Shinkawa H, Kawahara T, Shimizu A,
Yokoyama T, et al. Nomogram predicting long-term survival after the diagnosis of intrahepatic recurrence of hepatocellular carcinoma following an initial liver resection. Int $\mathrm{J}$ Clin Oncol 2017;22:715-725.

10. Poon RT, Fan ST, Lo CM, Liu CL, Wong J. Intrahepatic recurrence after curative resection of hepatocellular carcinoma: long-term results of treatment and prognostic factors. Ann Surg 1999;229:216-222.

11. Taura K, Ikai I, Hatano E, Fujii H, Uyama N, Shimahara Y. Implication of frequent local ablation therapy for intrahepatic recurrence in prolonged survival of patients with hepatocellular carcinoma undergoing hepatic resection: an analysis of 610 patients over 16 years old. Ann Surg 2006;244:265-273.

12. Matsumata T, Kanematsu T, Takenaka K, Yoshida Y, Nishizaki T, Sugimachi K. Patterns of intrahepatic recurrence after curative resection of hepatocellular carcinoma. Hepatology 1989;9:457460 .

13. Shimada K, Sakamoto Y, Esaki M, Kosuge T, Morizane C, Ikeda $\mathrm{M}$, et al. Analysis of prognostic factors affecting survival after initial recurrence and treatment efficacy for recurrence in patients undergoing potentially curative hepatectomy for hepatocellular carcinoma. Ann Surg Oncol 2007;14:2337-2347.

14. Huang WY, Jen YM, Lee MS, Chang LP, Chen CM, Ko KH, et al. Stereotactic body radiation therapy in recurrent hepatocellular carcinoma. Int J Radiat Oncol Biol Phys 2012;84:355361.

15. Jang WI, Kim MS, Bae SH, Cho CK, Yoo HJ, Seo YS, et al. High-dose stereotactic body radiotherapy correlates increased local control and overall survival in patients with inoperable hepatocellular carcinoma. Radiat Oncol 2013;8:250.

16. Jang WI, Bae SH, Kim MS, Han CJ, Park SC, Kim SB, et al. A phase 2 multicenter study of stereotactic body radiotherapy for hepatocellular carcinoma: safety and efficacy. Cancer 2020; 126:363-372.

17. Livraghi $\mathrm{T}$, Mäkisalo $\mathrm{H}$, Line $\mathrm{PD}$. Treatment options in hepatocellular carcinoma today. Scand J Surg 2011;100:22-29. 